\title{
CDISC SDTM Trial Summary Parameter Long Name Terminology
}

National Cancer Institute

\section{Source}

National Cancer Institute. CDISC SDTM Trial Summary Parameter Long Name

Terminology. NCI Thesaurus. Code C67152.

Terminology codelist used with Trial Summary Parameter Test Name within the Clinical Data Interchange Standards Consortium Study Data Tabulation Model. 